\title{
UPAYA IMPROVEMENT PENGENDALIAN PERSEDIAAN SUKU CADANG DENGAN METODE FIXED TIME PERIOD
}

\section{IMPROVEMENT EFFORTS IN SPARE PART INVENTORY CONTROL WITH FIXED TIME PERIOD METHOD}

\author{
Sazli Tutur Risyahadi' ${ }^{1)}$ dan Hanifah Yunan Putri' ${ }^{2)}$ \\ ${ }^{1,2)}$ Sekolah Vokasi Institut Pertanian Bogor, Kampus IPB Cilibende Jl. Kumbang No. 14, Bogor, 16151, Indonesia \\ Email korespondensi : sazlitutur@apps.ipb.ac.id
}

DOI Number : 10.30988/jmil.v3i2.122

\begin{abstract}
Perusahaan yang memiliki keinginan untuk memenangkan persaingan yang terus meningkat di era globalisasi, perlu terus menerus melakukan perbaikan metode pengendalian persediaan suku cadangnya. Metode existing di perusahaan memiliki beberapa kekurangan seperti belum mempertimbangkan standar deviasi demand dan service level yang dikehendaki oleh perusahaan. Tujuan kajian ini adalah melakukan perbaikan pengelolaan persediaan suku cadang dengan menerapkan model yang memiliki karakteristik pengadaan yang sesuai dengan perusahaan. Model Fixed Time Period (FTP) adalah model yang sesuai karena telah memenuhi karakteristik pengelolaan persediaan di perusahaan seperti pemesanan barang dengan interval waktu yang konstan dan demand yang berfluktuatif. Hasil menunjukkan bahwa jumlah pemesanan pada suku cadang bandsaw dengan menggunakan metode existing perusahaan di tahun 2018 selalu lebih tinggi quantity ordernya dibandingkan dengan menggunakan metode FTP. Berbeda dengan suku cadang bandsaw, suku cadang thermoc, jumlah order dengan metode FTP tidak selalu lebih rendah; bahkan metode FTP seringkali lebih tinggi atau pun sama quantity ordernya pada tahun 2018.
\end{abstract}

Kata Kunci: Analisis ABC, Metode Fixed Time Period, Manajemen Inventori

The company that has the desire to winning the increasing competition in the era of globalization need to improve the method of spare parts inventory control continually. Existing approaches in companies have several disadvantages such as not considering the standard deviation of demand and service level desired by the company. The purpose of this study is to improve the management of spare parts inventories by implementing a model that have right characteristics that are in line with the company. The Fixed Time Period (FTP) model is an appropriate model because it has fulfilled the characteristic of inventory management in companies such as ordering goods with constant time intervals and fluctuating demand. The results show that the number of orders on bandsaw parts using the existing company method in 2018 always has a higher order quantity than using the FTP method. Unlike bandsaw parts, thermoc parts, the number is not still lower; even the FTP method was often higher or equal to the order quantity in 2018.

Keywords: ABC Analysis, Fixed Time Period Methods, Inventory Management 


\section{PENDAHULUAN}

Setiap industri yang berdiri dengan prinsip berkelanjutan tentu akan memperhatikan cara dan metode terbaik untuk memenangkan persaingan yang terus meningkat pesat di era globalisasi. Begitu pula dengan PT XYZ, sebuah perusahaan manufaktur berlokasi di daerah industri sekitaran Jabodetabek dengan berbagai variasi produk saniter dan fittings di Indonesia. PT XYZ telah dikenal dengan reputasi pasar penjualan yang baik karena kualitas produk yang sangat baik.

Kualitas produk yang baik berkaitan erat dengan produktivitas yang ada di dalam perusahaan. Indeks produktivitas yang optimal dapat dilakukan dengan cara menghitung total nilai masing-masing input dan output [1] dan produktivitas yang optimal akan dicapai perusahaan dengan cara meminimumkan input [2]. Bila perusahaan berhasil untuk mengoptimalkannya maka akan diperoleh manfaat seperti mengurangi biaya pembelian, biaya penyimpanan maupun biaya pemesanan [3].

Kondisi mesin yang prima atau tahan terhadap kerusakan akan membantu pengoptimalan produktivitas, namun sulitnya memprediksi kapan mesin mengalami kerusakan (breakdown) akan menyebabkan diperlukannya ketersediaan suku cadang komponen yang memadai pada saat-saat dibutuhkan [3]. Suku cadang merupakan salah satu inventori yang perlu ditangani agar memberikan manfaat optimal bagi perusahaan [4].

Untuk memberikan manfaat yang optimal bagi perusahaan khususnya pada pengelolaan spare part, metode pemesanan yang ada pada saat ini perlu di improve karena memiliki beberapa kekurangan diantaranya adalah belum mempertimbangkan standar deviasi demand dan service level yang dikehendaki oleh perusahaan. Padahal kedua hal tersebut dapat mempengaruhi fluktuasi quantity order yang merupakan salah satu bagian dari masalah yang sedang dihadapi oleh PT XYZ saat ini. Data historis menunjukkan bahwa perusahan tidak memesan suku cadang thermoc pada bulan September dan Oktober 2018, sehingga terjadi kekurangan persediaan yang mengakibatkan pekerjaan tertunda karena harus menunggu pemesanan suku cadang selanjutnya [4]. Namun pada bulan November 2018 perusahan memesan berlebih sebesar 38 unit thermoc. Pemesanan pada bulan November 2018 tersebut jauh melebihi rata-rata pemesanan perbulan sebesar 20 unit per bulan.

Berdasarkan kekurangan dari metode existing perusahaan, maka perlu mencari model persediaan yang tepat sesuai dengan karakteristik pengadaan di PT XYZ. Karakteristik pertama yaitu PT XYZ melakukan pemesanan setiap awal bulan dengan jumlah pesanan berbeda-beda setiap bulannya. Karakteristik kedua yaitu tingkat pemakaian suku cadang pun tidak konstan melainkan berfluktuatif. Karakteristik ketiga yaitu PT XYZ selalu berusaha meminimalkan kekurangan stok suku cadang sehingga nilai service level yang tinggi diperlukan untuk menjamin lancarnya proses produksi.

Berdasarkan karakteristik tersebut maka model yang tepat adalah model Fixed Time Period (FTP) karena kelebihan metode ini sudah menggunakan standar deviasi demand yang lebih detail untuk perhitungan safety stock nya dan sangat cocok untuk demand yang berfluktuatif. Selain itu, kelebihan dari metode fixed time period adalah :

1.Administrasi sistem mudah karena penambahan kembali dapat dilakukan pada periode tetap.

2.Pemesanan untuk banyak item dari supplier yang sama dapat digabungkan dalam satu pesanan pembelian (purchase order)

3.Posisi persediaan dapat diketahui hanya saat pemeriksaan ulang terjadi (tidak berkelanjutan seperti dalam fixed order quantity) [5]. 
Metode FTP yang memiliki karakteristik rentang pemesanan persediaan barang dibuat pada waktu yang tetap dan teratur [6] telah digunakan pada industri remanufacturing yaitu pada PT Komatsu Reman Indonesia (KRI) dan telah mendapatkan hasil dari quantity order yang memadai dibandingkan dengan metode existing perusahaan dan dapat meminimalisir terjadinya stockout [5]. Selanjutnya metode FTP yang pembelian barangnya dengan menggunakan penetapan interval tertentu [7] juga sudah dibuktikan pada studi kasus di PT Adi Putro Wirasejati dengan pernyataan bahwa metode FTP dapat menjadi pertimbangan metode yang lebih baik bagi perusahaan karena peningkatan service level yang cukup signifikan dan penurunan total biaya di beberapa suku cadang yang telah diamati [15].

Tujuan kajian ini adalah melakukan perbaikan pengelolaan persediaan suku cadang dengan menerapkan model Fixed Time Period khususnya pada PT XYZ dengan didahului oleh ketetapan analisis ABC yang sudah ada di perusahaan, lalu dilanjutkan dengan perbaikan pada quantity order didapat dengan cara membandingkan hasil dari metode existing yang dilakukan oleh PT XYZ dengan hasil dari metode FTP. Ukuran perbandingan yang diukur adalah jumlah order yang dipesan ke supplier atau dapat juga dilihat selisih dari biaya pembelian suku cadang selama setahun.

\section{METODE PENELITIAN}

Kajian upaya improvement pengendalian persediaan suku cadang dengan metode fixed time period yaitu melalui observasi langsung, wawancara, dan bersumber dari studi literatur yang telah dikumpulkan dari berbagai sumber referensi yang ada dan kemudian dipelajari juga dipahami agar analisa data dapat disajikan dan sesuai dengan berbagai sumber referensi. Pencantuman sumber sudah dituliskan di dalam daftar pustaka menggunakan software mendeley. Gambaran alur tahapan metode penelitian dapat dilihat pada Gambar 1.

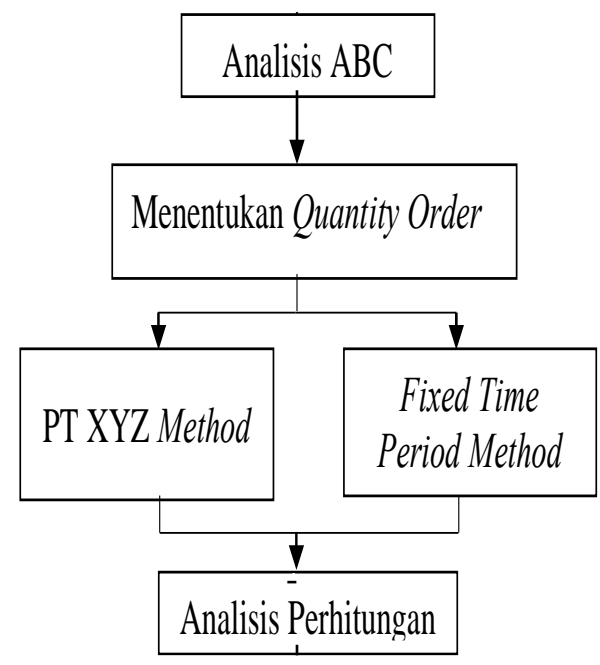

Gambar 1. Alur Tahapan Penelitian

Kegiatan yang dilakukan adalah dengan mengidentifikasi permasalahan yang terjadi di PT XYZ, tujuan dari identifikasi masalah adalah menemukan penyebab terjadinya masalah di perusahaan. Setelah itu masalah dirumuskan agar dapat menjadi acuan untuk menemukan tujuan kajian. Permasalahan yang terjadi di PT XYZ adalah ketika demand sangat berfluktuatif dan ketika quantity order ditentukan, terkadang hasilnya tidak sesuai maka terjadi kekurangan atau kelebihan stock.

\subsection{Analisis ABC}

Metode analisis $\mathrm{ABC}$ ini digunakan untuk memberikan penekanan pada golongan atau jenis-jenis bahan yang terdapat dalam persediaan yang mempunyai nilai penggunaan yang relatif tinggi/mahal. Biasanya metode analisis ini digunakan dalam perusahaanperusahaan yang mempunyai berbagai jenis atau macam bahan dalam persediaan yang mempunyai nilai penggunaan yang berbedabeda. Metode analisis ABC ini menggunakan "Pareto Analysis", yang menekankan bahwa sebagian kecil dari jenis-jenis bahan yang terdapat dalam persediaan mempunyai nilai penggunaan yang cukup besar yang 
mencakup kira-kira lebih daripada $60 \%$ dari seluruh nilai penggunaan bahan yang terdapat dalam persediaan[8].

\subsection{Penentuan Quantity Order}

Menentukan quantity order spare part yang berasal dari supplier lokal di PT XYZ dapat dilakukan dengan dua cara yaitu:

\section{Metode Existing PT XYZ}

Metode yang digunakan oleh PT XYZ selama ini untuk melakukan pemesanan spare part yaitu dengan cara: Mengumpulkan data yang terkait seperti demand dalam empat bulan sebelumnya (1 periode), lead time, order cycle, safety stock, dan total inventory. Rumus dan penjelasannya sebagaimana berikut :

Rumus Quantity Order dari PT XYZ adalah:

$$
Q O=(A+B+C)-(D+E)
$$

Keterangan :

$\mathrm{UM}=$ Use Month yaitu rata-rata penggunaan dalam satu periode 4 bulan terakhir

QO =Quantity Order dari total jumlah yang telah dihitung.

LT =Lead Time selama pemesanan ditentukan secara pasti adalah 2 bulan.

$\mathrm{OO}=$ Order Cycle pemesanan barang ditentukan secara pasti adalah 1 bulan.

SS = Safety Stock dari persediaan ditentukan yaitu dengan cara mengalikan 1 dengan use month.

$A=\mathrm{LT} \times \mathrm{UM}$

$B=\mathrm{OO} \times \mathrm{UM}$

$C=\mathrm{SS} \times \mathrm{UM}$

$D=$ Ready Stock penyimpanan barang yang ada di gudang.

$E=$ On Order yaitu pemesanan yang akan datang, masih dalam tahap perjalanan.

Pemesanan dilakukan secara teratur dan konstan yaitu setiap awal bulan. Barang yang dipesan adalah spare part yang memiliki karakteristik independent (tidak bergantung dengan barang lainnya).

2. Metode Fixed Time Period

Metode Fixed Time Period adalah Model pengendalian persediaan yang dijelaskan oleh [6] yang dikenal sebagai Fixed Period System dimana rentang pemesanan persediaan barang dibuat pada waktu yang tetap dan teratur. Fixed period system diterapkan ketika jangka waktu antara pemesanan (lead time) adalah konstan, dan setiap barang tidak bergantung antara satu dengan yang lainnya (independent). metode pembelian dengan sistem FOI merupakan pembelian dengan metode penetapan interval tertentu dalam memenuhi permintaan atau kebutuhan bahan baku [7].

Model $\mathrm{P}$ berbeda dengan model $\mathrm{Q}$ atau model probabilistik lainnya dikarenakan Model $\mathrm{P}$ telah mengetahui waktu pasti interval pemesanannya[3]. Karakteristik kebijakan inventori model $\mathrm{P}$ ditandai oleh 2 elemen dasar sebagai berikut.

1. Pemesanan dilakukan menurut suatu selang interval waktu yang tetap (T).

2. Ukuran lot pemesanan $\left(q_{0}\right)$ besarnya merupakan selisih antara inventori maksimum yang diinginkan $(\mathrm{R})$ dengan inventori yang ada pada saat pemesanan dilakukan (r).

Rumus dari metode fixed time period adalah

$$
q=\bar{d}(T+L)+z \sigma_{T+L}-I
$$

keterangan:

$q$ = jumlah yang harus dipesan

$\bar{d} \quad=$ permintaan rata-rata

$T=$ jumlah periode antar pemeriksaan ulang berikutnya

$L \quad=$ waktu tunggu dalam periode (Lead Time)

$z \quad=$ service level

$\sigma_{T+L}=$ standar deviasi

I $=$ tingkat persediaan yang ada 
Permintaan rata-rata yang didapat dari empat bulan sebelumnya. Jumlah periode antar pemeriksaan ulang berikutnya dikenal sebagai order cycle yaitu selama 1 bulan. Lead Time adalah waktu tunggu yang diperlukan ketika melakukan pemesanan yaitu selama 2 bulan. Service level yang dikehendaki untuk dipenuhi adalah 95\% dan sebanyak 5\% diberikan kelonggaran dengan diperbolehkan untuk tidak terpenuhi.

Perhitungan persediaan suku cadang diolah dengan menggunakan Microsoft Excel. Tahap ini dilakukan perhitungan quantity order dari suku cadang kategori A yaitu suku cadang dengan tingkat nilai yang tinggi dan mendominasi dibandingkan dengan nilai suku cadang lainnya.

\section{HASIL DAN PEMBAHASAN}

Persediaan di PT XYZ dikategorikan menjadi empat jenis yaitu:

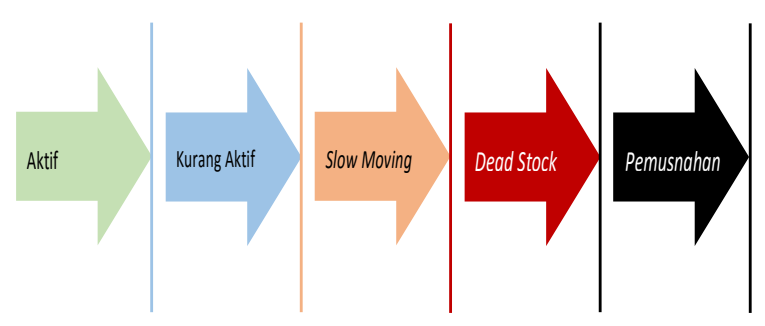

Gambar 2. Alur kategori persediaan di PT XYZ

Gambar 2 menjelaskan bahwa alur kategori persediaan di PT XYZ bergantung intensitas pemakaian barang. Kondisi pemakaian barang yang mempengaruhi kategori persediaan di PT XYZ, yaitu :

1. Aktif yaitu minimal dalam tiga bulan ada pemakaian.

2. Kurang aktif minimal dalam empat bulan ada pemakaian.

3. Slow Moving lebih dari sama dengan 12 bulan tidak terdapat pemakaian

4. Dead Stock telah menjadi status slow moving selama lebih dari satu tahun.
Khusus pada barang aktif aturan penempatannya adalah di dekat aktivitas kerja dengan menerapkan posisi tetap, jumlah tetap dan arah tetap. Fokus pengendalian spare part di PT XYZ adalah pada barang yang berstatus aktif, dan berasal dari supplier lokal.

Suku cadang juga dibagi menjadi repairable spare merupakan komponen yang rusak dan dapat dikembalikan ke keadaan operasionalnya dengan cara diperbaiki. Sedangkan komponen non-repairable merupakan komponen yang ketika dilakukan perbaikan akan sangat sulit untuk dilakukan bahkan tidak memungkinkan atau justru biaya perbaikan itu sendiri lebih besar daripada biaya pembelian komponen; sehingga akan lebih baik untuk menggantinya langsung[9].

\subsection{Analisis ABC}

Analisis klasifikasi ABC memiliki beberapa manfaat bagi PT XYZ, diantaranya sebagai berikut:

1. Membantu manajemen dalam menentukan tingkat persediaan yang optimum.

2. Memberikan perhatian pada jenis persediaan utama (kategori A) karena dapat memberikan cost benefit kepada perusahaan.

Kategori $\mathrm{ABC}$ lebih rinci akan dijelaskan pada tabel 1.

Tabel 1. Kategori ABC pada PT XYZ

\begin{tabular}{lcc}
\hline Kategori & Total Item & Nilai (\%) \\
\hline A & 2 item & 71,2798 \\
B & 9 item & 18,6878 \\
C & 53 item & 10,0324 \\
\hline
\end{tabular}

Tabel 1 menjelaskan bahwa analisis $\mathrm{ABC}$ yang sudah menjadi ketetapan perusahaan pada bagian suku cadang telah mengelompokkan suku cadang menjadi tiga kategori yaitu kategori A adalah barangbarang yang memiliki nilai tinggi dan perlu ditangani dengan serius, kategori B adalah barang-barang yang memiliki nilai sedang, 
dan kategori $\mathrm{C}$ adalah barang-barang yang memiliki nilai rendah. Analisis ABC yang dijelaskan pada grafik dan tabel di atas akan berfokus pada kategori A biasanya berjumlah $10-20 \%$ dari total jumlah persediaan dan mempresentasikan $60-80 \%$ dari total nilai. Kategori A pada PT XYZ adalah pada part Band Saw 20X0.8X8 dengan persen nilai sebesar 39,3427\% dan part Thermoc. with conec head dengan persen nilai sebesar $31,9371 \%$ maka total persen nilai dari kedua spare part tersebut adalah sebesar $71,2798 \%$ menempati tingkat tertinggi dibandingkan nilai spare part lainnya.

Analisis $\mathrm{ABC}$ memberikan penekanan pada golongan atau jenis-jenis bahan yang mempunyai nilai penggunaan yang relatif tinggi atau mahal [8]. Pengendalian persediaan pada kategori A tentu akan berbeda dengan pengendalian kategori $\mathrm{B}$ maupun C, khusus pada kategori A di PT XYZ pengendalian barangnya akan diutamakan karena memiliki nilai yang lebih tinggi. Untuk itu, dengan melakukan klasifikasi ABC ini, dalam menentukan pengendalian persediaan dapat difokuskan pada item-item yang bernilai besar yang masuk kategori A karena akan mengakibatkan kerugian yang besar bagi perusahaan jika tidak dikendalikan dengan tepat [10].

\subsection{Improvement Kategori A}

PT XYZ menerapkan formula tersendiri yang sudah digunakan sejak lama, namun perhitungan metode existing lebih sederhana dibandingkan metode fixed time period yang menggunakan banyak macam data yang berfungsi untuk meningkatkan nilai akurasi hasil perhitungan. PT XYZ memiliki waktu interval pemesanan yang selalu sama atau tetap pada setiap awal bulan namun dengan jumlah (quantity) pemesanan yang berbedabeda pada setiap bulan. Kategori barang yang akan dipesan berupa spare part yang memiliki sifat tidak berkaitan dengan barang lainnya dan probabilistik dimana lead time konstan dan demand berfluktuatif. Pemesanan akan digabungkan dalam satu pembelian. Tabel 2 di bawah ini akan memberikan data mengenai demand yang ada di PT XYZ.

Tabel 2. Data demand

\begin{tabular}{lcc}
\hline Bulan & $\begin{array}{c}\text { Band Saw } \\
\text { 20X0.8X8 } \\
\text { (roll) }\end{array}$ & $\begin{array}{c}\text { Thermoc } \\
\text { with conec } \\
\text { head (pcs) }\end{array}$ \\
\hline Sept 2017 & 28 & 16 \\
Okt 2017 & 17 & 20 \\
Nov 2017 & 16 & 19 \\
Des 2017 & 14 & 12 \\
Jan 2018 & 10 & 10 \\
Feb 2018 & 10 & 8 \\
Mar 2018 & 13 & 7 \\
Apr 2018 & 18 & 10 \\
Mei 2018 & 21 & 18 \\
Juni 2018 & 13 & 10 \\
Juli 2018 & 17 & 17 \\
Ags 2018 & 17 & 9 \\
Sept 2018 & 15 & 6 \\
Okt 2018 & 13 & 26 \\
Nov 2018 & 11 & 4 \\
Des 2018 & 12 & 13 \\
\hline
\end{tabular}

Tabel 2 memaparkan data mengenai demand yang ada di PT XYZ pada tahun 2018 dari mulai bulan Januari hingga bulan Desember. Terlihat bahwa permintaan terhadap kedua jenis suku cadang tersebut berfluktuatif, sehingga untuk memenuhinya perlu ditentukan service levelnya, semakin tinggi rasio layanan, maka persediaan semakin mampu untuk memenuhi permintaan yang datang berarti pengelolaan persediaan semakin efektif [11]. Rasio Layanan atau service level merupakan salah satu parameter untuk mengukur tingkat efektivitas dari persediaan barang. Artinya semakin tinggi rasio layanan, maka persediaan semakin mampu untuk memenuhi permintaan yang datang berarti pengelolaan persediaan semakin efektif [12]. Dengan peningkatan nilai service level ini, perusahaan PT XYZ dapat meminimalkan terjadinya proses produksi yang terhenti akibat tidak tersedianya suku cadang saat terjadi kerusakan mesin produksi. Dengan proses 
produksi yang lancar tersebut, PT XYZ tidak perlu menambah jam kerja untuk mengejar target produksi yang sesuai dengan kajian [13]. Service level yang dikehendaki oleh PT $\mathrm{XYZ}$ adalah $95 \%$ sehingga diperoleh nilai $\mathrm{Z}$ adalah 1,65. Berikut penerapan metode existing PT XYZ dan metode fixed time period untuk spare part Band Saw 20X0.8X8 dapat dilihat pada tabel di bawah ini.

Tabel 3. Metode Existing PT XYZ part Band Saw 20X0.8X8

\begin{tabular}{lcccc}
\hline Bulan & SS & $\bar{d}$ & $\mathrm{I}$ & $\mathrm{q}$ \\
\hline Jan 2018 & 18,75 & 18,75 & 50 & 25 \\
Feb 2018 & 15,25 & 15,25 & 39 & 18 \\
Mar 2018 & 12,5 & 12,5 & 56 & 0 \\
Apr 2018 & 11,75 & 11,75 & 44 & 3 \\
Mei 2018 & 12,75 & 12,75 & 39 & 12 \\
Juni 2018 & 15,25 & 15,25 & 39 & 22 \\
Juli 2018 & 15,75 & 15,75 & 26 & 37 \\
Ags 2018 & 16,25 & 16,25 & 42 & 23 \\
Sept 2018 & 16,5 & 16,5 & 48 & 18 \\
Okt 2018 & 14,75 & 14,75 & 55 & 4 \\
Nov 2018 & 15,25 & 15,25 & 41 & 20 \\
Des 2018 & 14 & 14 & 49 & 7 \\
\hline
\end{tabular}

$\underline{\text { Tabel } 3}$ menjelaskan mengenai perhitungan untuk mendapatkan quantity order di PT XYZ dengan menggunakan metode yang ada di perusahaan. Contoh perhitungan metode existing di PT XYZ pada bulan Januari 2018 adalah dengan menghitung rata-rata use month dari empat bulan sebelumnya, yaitu 28,17,16,14.

Use month yang didapatkan adalah 18,75. Lalu dilanjutkan dengan menghitung safety stock dari PT XYZ adalah 1xUM yaitu 18,75 . Hasil inventory adalah penjumlahan dari ready stock dan on order. Lalu didapatkan quantity order. Tabel 4 di bawah ini akan memberikan penjelasan mengenai data perhitungan dengan menggunakan metode fixed time period.

Tabel 4. Metode Fixed Time Period PT XYZ part Band Saw 20X0.8X8

\begin{tabular}{lcccc}
\hline Bulan & SS & $\bar{d}$ & I & q \\
\hline Jan 2018 & 17,92 & 18,75 & 50 & 25 \\
\hline
\end{tabular}

\begin{tabular}{lcccc}
\hline Bulan & SS & $\bar{d}$ & I & q \\
\hline Feb 2018 & 8,82 & 14,25 & 39 & 13 \\
Mar 2018 & 8,55 & 12,5 & 56 & 0 \\
Apr 2018 & 5,88 & 11,75 & 44 & 0 \\
Mei 2018 & 10,75 & 12,75 & 39 & 11 \\
Juni 2018 & 13,03 & 15,25 & 39 & 20 \\
Juli 2018 & 11,00 & 15,75 & 26 & 33 \\
Ags 2018 & 9,97 & 16,25 & 42 & 17 \\
Sept 2018 & 9,45 & 16,5 & 48 & 11 \\
Okt 2018 & 9,61 & 14,75 & 46 & 0 \\
Nov 2018 & 6,73 & 15,25 & 41 & 12 \\
Des 2018 & 7,36 & 14 & 49 & 1 \\
\hline
\end{tabular}

Penjelasan dari tabel 4 di atas adalah data dari perhitungan metode fixed time period, dimana terdapat penggunaan tingkat rasio layanan dan standar deviasi demand sebagai data yang akan mempengaruhi hasil perhitungan. Contoh perhitungan metode Fixed Time Period di PT XYZ pada bulan Januari 2018 adalah dengan menghitung rata-rata use month dari empat bulan sebelumnya, yaitu 28,17,16,14. Use month yang didapatkan adalah 18,75. Lalu dilanjutkan dengan menghitung safety stock dari metode FTP adalah dengan menghitung service level sebesar 95\% karena kategori yang diamati adalah kategori A. Lalu dikalikan dengan standar deviasi demand. Hasil inventory adalah penjumlahan dari ready stock dan on order. Lalu didapatkan quantity order.

Service level dikalikan dengan $\sigma_{T+L}$ akan menjadi safety stock. Jumlah safety stock bergantung pada dua hal yaitu standar deviasi permintaan selama lead time ( $\sigma \mathrm{DL})$ dan nilai $\mathrm{z}$ dari service level. Untuk $\sigma \mathrm{DL}$ yang bernilai besar maka jumlah safety stock nya lebih banyak dibandingkan nilai $\sigma D L$ yang lebih kecil. Jumlah safety stock yang dipengaruhi oleh nilai z menunjukkan bahwa semakin besar nilai z maka semakin besar juga nilai safety stock nya. Hal tersebut bertujuan agar permintaan yang memiliki service level tinggi dapat tetap terpenuhi dan dipertahankan nilai service level nya. Sedangkan untuk nilai service level kecil, tetapi $\sigma D L$ besar mempunyai safety stock yang besar. Hal tersebut bertujuan untuk 
mengantisipasi pergerakan permintaan yang tidak stabil[14]. Terakhir adalah Inventory yaitu merupakan jumlah persediaan yang terdapat di dalam gudang. Grafik perbandingan metode existing dengan metode FTP part Bandsaw dapat dilihat pada gambar 3 .

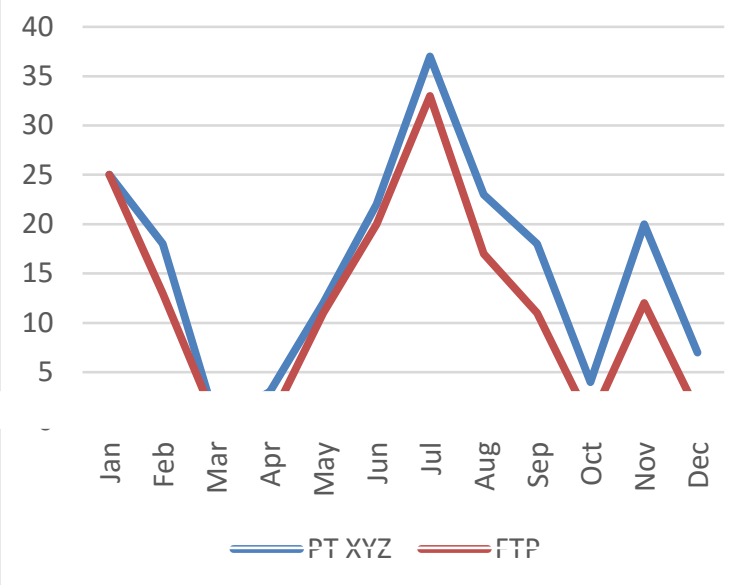

Gambar 3. Grafik Part Band Saw

Berdasarkan dari grafik tersebut, terlihat bahwa metode yang digunakan oleh perusahaan saat ini selalu lebih tinggi quantity ordernya dibandingkan dengan menggunakan metode FTP pada setiap bulannya, Hal ini menunjukkan bahwa metode FTP mampu melakukan improvement persediaan. Salah satu penyebabnya adalah standar deviasi demand untuk 4 periode selama satu tahun cenderung lebih rendah dibandingkan suku cadang lain. Bandsaw memiliki karakteristik permintaan yang cenderung bersifat rutin. Suku cadang seperti pisau yang akan tumpul pada saat digunakan dengan frekuensi tinggi dan terus-menerus. Bandsaw yang baru akan digunakan bila bandsaw yang ada saat ini sudah mulai tumpul sehingga termasuk ke dalam consumable spare part, suku cadang ini pun digunakan untuk berbagai jenis produk yang dihasilkan oleh PT XYZ pada proses pengecoran sehingga secara agregat, jumlah produk yang menggunakan fasilitas bandsaw cenderung stabil.

Adapun metode existing yang digunakan oleh PT XYZ pada pengendalian persediaan bandsaw tidak memperhatikan nilai standar deviasi tingkat penggunaan suku cadang bandsaw. Perusahaan hanya menggunakan rata-rata empat bulan terakhir sebagai acuan menentukan jumlah order. Kelemahan metode ini tidak menggambarkan karakteristik fluktuasi penggunaan, seharusnya semakin tidak berfluktuasi demand maka semakin rendah quantity ordernya.

Harga dari part bandsaw berdasarkan survey yang dijual di pasaran berada pada rata-rata kisaran Rp 1.400.000 per roll dan total quantity order pada metode existing di tahun 2018 adalah 189 roll. Maka hasil dari biaya yang harus dikeluarkan untuk membeli bandsaw adalah $\mathrm{Rp}$ 264.600.000. lalu dibandingkan dengan metode fixed time period dengan total quantity order pada tahun 2018 adalah 143 dan jumlah biaya yang harus dikeluarkan untuk membeli adalah Rp 200.200.000. Selisih yang didapatkan dari perbandingan dua metode tersebut adalah $\mathrm{Rp}$ 64.400.000.

Penjelasan mengenai penerapan metode existing PT XYZ dan metode fixed time period untuk part thermoc with conec head p. $400 \mathrm{~mm}$ dapat dilihat pada tabel di bawah ini :

Tabel 5. Metode Existing PT XYZ part Thermoc with conec head.

\begin{tabular}{lcccc}
\hline Bulan & SS & $\bar{d}$ & I & q \\
\hline Jan 2018 & 16,75 & 16,75 & 19 & 48 \\
Feb 2018 & 15,25 & 15,25 & 25 & 36 \\
Mar 2018 & 12,25 & 12,25 & 41 & 8 \\
Apr 2018 & 9,25 & 9,25 & 34 & 3 \\
Mei 2018 & 8,75 & 8,75 & 25 & 10 \\
Juni 2018 & 10,75 & 10,75 & 25 & 18 \\
Juli 2018 & 10,75 & 10,75 & 18 & 25 \\
Ags 2018 & 13,25 & 13,25 & 1 & 52 \\
Sept 2018 & 12,5 & 12,5 & 74 & 0 \\
Okt 2018 & 10 & 10 & 46 & 0 \\
Nov 2018 & 14,5 & 14,5 & 20 & 38 \\
Des 2018 & 11,25 & 11,25 & 56 & 11 \\
\hline
\end{tabular}

$\underline{\text { Tabel } 5}$ memaparkan mengenai hasil perhitungan untuk mendapatkan jumlah quantity order di PT XYZ dengan menggunakan metode yang ada (existing) di 
perusahaan. Contoh perhitungan metode existing di PT XYZ pada bulan Januari 2018 adalah dengan menghitung rata-rata use month dari empat bulan sebelumnya, yaitu $16,20,19,12$. Use month yang didapatkan adalah 16,75. Lalu dilanjutkan dengan menghitung safety stock dari PT XYZ adalah 1xUM yaitu 16,75. Hasil inventory adalah penjumlahan dari ready stock dan on order. Lalu didapatkan quantity order. Tabel $\mathbf{6}$ akan menjelaskan mengenai perhitungan quantity order dengan menggunakan metode fixed time period.

Tabel 6. Metode Fixed Time Period PT XYZ part Thermoc with conec head.

\begin{tabular}{lcccc}
\hline Bulan & SS & $\bar{d}$ & $\mathrm{I}$ & $\mathrm{q}$ \\
\hline Jan 2018 & 10,24 & 16,75 & 19 & 42 \\
Feb 2018 & 14,22 & 15,25 & 25 & 35 \\
Mar 2018 & 13,64 & 12,25 & 41 & 10 \\
Apr 2018 & 6,32 & 9,25 & 34 & 1 \\
Mei 2018 & 4,27 & 8,75 & 25 & 6 \\
Juni 2018 & 14,22 & 10,75 & 25 & 22 \\
Juli 2018 & 14,22 & 10,75 & 18 & 29 \\
Ags 2018 & 14,22 & 13,25 & 1 & 53 \\
Sept 2018 & 16,53 & 12,5 & 74 & 0 \\
Okt 2018 & 17,65 & 10 & 46 & 2 \\
Nov 2018 & 25,53 & 14,5 & 20 & 49 \\
Des 2018 & 28,62 & 11,25 & 56 & 6 \\
\hline Penjelasan & dari & tabel & adalah & data-data
\end{tabular}

Penjelasan dari tabel 6 adalah data-data yang diperoleh dari hasil perhitungan dengan menggunakan metode fixed time period, dimana tingkat rasio layanan (service level) dan standar deviasi demand sebagai data yang harus ada karena akan akan mempengaruhi hasil perhitungan. Contoh perhitungan metode Fixed Time Period di PT XYZ pada bulan Januari 2018 adalah dengan menghitung rata-rata use month dari empat bulan sebelumnya, yaitu $16,20,19,12$. Use month yang didapatkan adalah 16,75. Lalu dilanjutkan dengan menghitung safety stock dari metode FTP adalah dengan menghitung service level sebesar 95\% karena kategori yang diamati adalah kategori A. Lalu dikalikan dengan standar deviasi demand. Hasil inventory adalah penjumlahan dari ready stock dan on order. Lalu didapatkan quantity order.
Berikut adalah gambar grafik perbandingan metode existing dengan metode FTP pada part Thermoc.

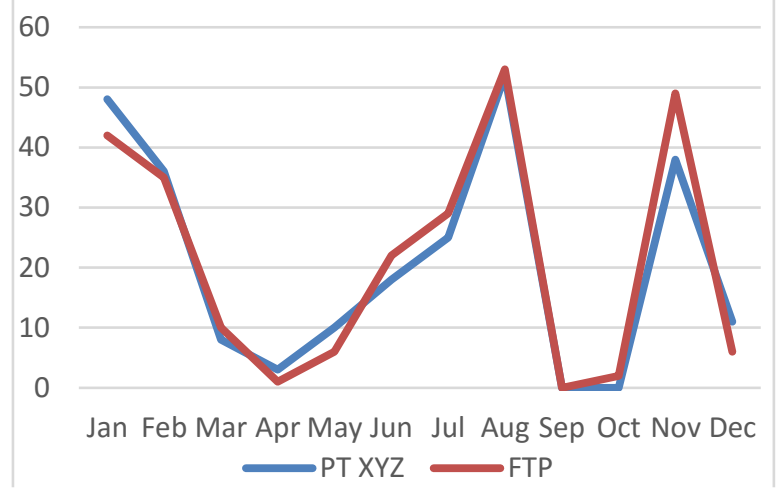

Gambar 4. Grafik Part Thermoc.

Grafik diatas menunjukkan bahwa jumlah order dengan metode FTP tidak selalu lebih rendah, terlihat bahwa metode FTP lebih tinggi atau pun sama quantity ordernya dibandingkan dengan metode existing PT XYZ terutama dari bulan Juni hingga Desember 2018. Penyebab hal tersebut adalah tingginya standar deviasi penggunaan suku cadang thermoc, suku cadang ini berfungsi sebagai alat untuk menjamin suhu cairan bahan baku agar selalu memenuhi standar pada proses pengecoran yang tidak rutin pergantiannya, hanya digunakan bila terjadi kerusakan pada mesin. Berdasarkan pengamatan, frekuensi kerusakan agak sulit diprediksi sehingga meningkatkan fluktuasi demandnya yang diinterpretasikan dengan nilai standar deviasi. Dengan menggunakan metode FTP, walaupun jumlah order lebih tinggi, tapi tingkat ketersediaan lebih terjamin sebagai bentuk antisipasi ketiadaan thermoc pada keadan mesin rusak. Adapun metode existing PT XYZ tidak menggunakan nilai standar deviasi sehingga akan mengurangi daya antisipasi bila terjadi fluktuasi penggunaan thermoc. PT XYZ hanya menghitung rata-rata 4 bulan terakhir sebagai acuan jumlah order pada periode selanjutnya, padahal tingkat penggunaan thermoc 
Walaupun demikian, dengan jumlah order yang lebih rendah dapat meminimasi biaya persediaan thermoc.

Harga dari part thermoc berdasarkan survey di pasaran berada pada rata-rata kisaran $\mathrm{Rp}$ 1.300 .000 per pes dan total quantity order pada metode existing di tahun 2018 adalah 249 pcs. Maka hasil dari biaya yang harus dikeluarkan untuk membeli thermoc adalah Rp 323.700.000. lalu dibandingkan dengan metode fixed time period dengan total quantity order pada tahun 2018 sebanyak 255 pcs dan jumlah biaya yang harus dikeluarkan untuk membeli thermoc adalah Rp 331.500.000. Selisih yang didapatkan dari perbandingan dua metode tersebut adalah Rp 7.800.000. Walaupun lebih tinggi biaya order dengan metode FTP, tetapi lebih menjamin ketersediaan Thermoc yang penggunaan sulit diprediksi.

\section{KESIMPULAN}

Upaya improvement pengelolaan persediaan di PT XYZ telah dilakukan dengan didahului oleh analisis ABC lalu perbandingan model existing dengan model Fixed Time Period (FTP). Analisis ABC menunjukkan bahwa suku cadang bandsaw dan thermoc termasuk kategori A. Hasil dari jumlah pemesanan pada suku cadang bandsaw dengan menggunakan metode existing adalah 189 roll dan selalu lebih tinggi quantity ordernya dibandingkan dengan menggunakan metode FTP yaitu 143 roll. Hal ini dikarenakan bandsaw tingkat penggunaannya tidak terlalu berfluktuatif. Berbeda dengan suku cadang bandsaw, suku cadang thermoc, jumlah order dengan metode FTP tidak selalu lebih rendah dengan hasil perhitungan 255 pcs, dibandingkan dengan metode existing PT XYZ yaitu 249 pcs. Sebagai dampaknya, bila PT XYZ menggunakan metode FTP, maka biaya pembelian akan lebih tinggi. Namun lebih menjamin ketersediaan Thermoc yang penggunaan cenderung sulit diprediksi terbukti dengan adanya permasalahan kekurangan stock di bulan September dan Oktober pada part Thermoc.

Setelah ditambah dengan perhitungan harga dari tiap part dan dibandingkan dengan kedua metode tersebut dapat diketahui bahwa metode fixed time period memiliki akurasi yang lebih tinggi untuk meningkatkan improvement hasil perhitungan dari quantity order nya karena sudah melibatkan analisis $\mathrm{ABC}$, standar deviasi permintaan dan nilai rasio layanan yang dikehendaki oleh perusahaan. Penelitian lanjutan dapat dilakukan beberapa skenario perhitungan FTP dengan menggunakan data historis dengan periode perhitungan yang berbeda-beda baik lebih dari empat bulan maupun kurang dari empat bulan. Selain itu, penelitian lanjutan dapat dilakukan dengan memasukan fungsi umur pakai suku cadang untuk melakukan forecasting sehingga jumlah yang diorder lebih akurat baik bandsaw maupun thermoc.

\section{DAFTAR PUSTAKA}

[1] A. Bakar, O. Suprianto, and Y. Yuniati, "Usulan Peningkatan Produktivitas Berdasarkan Metode Mundel Dan APC Di PT. Raffsya Media," J. Ind. Eng. Manag., vol. 2, no. 2, pp. 1-13, 2017.

[2] M. Octaviana, I. Baihaqi, and G. W. Bramanti, "Kebijakan Persediaan Spare Parts: Studi Kasus Pabrik Perakitan Sepeda Motor," J. Tek. ITS, vol. 7, no. 1, pp. A45-A49, 2018.

[3] S. N. Bahagia, Sistem Inventori. Bandung: Penerbit ITB, 2006.

[4] A. Ristono, Manajemen Persediaan. Yogyakarta: Graha Ilmu, 2009.

[5] M. Haris, "Optimalisasi Sistem Persediaan Spare Parts Fuel Injection Pump pada Perusahaan Remanufacturing dengan Metode Fixed Time Period with Safety Stock," Skripsi, Dept.Teknik Industri, Page | 138 
Universitas Indonesia, 2010.

[6] J. Heizer and B. Render, Manajemen Operasi, 11th ed. Jakarta: Salemba Empat, 2009.

[7] M. . Sukamto, "Analisis pengendalian persediaan bahan baku dengan metode fixed order interval (foi) terhadap biaya total persediaan dan laba operasi pada restoran benedict," J. Mozaik, vol. IX, no. 1, pp. 81-93, 2017.

[8] S. Assauri, Manajemen Produksi dan Operasi. Jakarta: Lembaga Penerbit Fakultas Ekonomi Universitas Indonesia, 2008.

[9] F. Tatas Dwi Atmaji and P. Agung Ngurah Nanda Utama, "Kebijakan Persediaan Suku Cadang Di PT ABC Menggunakan Metode RCS ( Reliability Centered Spares )," J. Manaj. Ind. Dan Logistik, vol. 2, no. 1, pp. 90-102, 2018.

[10] H. Ahyadi and S. Khodijah, "Analisis Pengendalian Persediaan Suku Cadang Pesawat B737-Ng Dengan Pendekatan Model Periodic Review Di Pt. X," Bina Tek., vol. 13, no. 1, pp. 47-58, 2017.

[11] I. Farida and M. N. Rozini, "Pengendalian Persediaan Spare Part Dan Pengembangan Dengan Konsep 80-20 ( Analisis Abc ) Pada Gudang Suku Cadang Pt . Astra International Tbk - Daihatsu," Semin. Nas. IPTEK Terap., vol. 1, no. 1, pp. 163-169, 2016.

[12] A. Meilani, "Pengendalian Persediaan Spare Part dan Pengembangan dengan Konsep 80-20 (Analisis ABC) pada AUTO2000 Cabang Sutoyo Malang," J. Ilm. Mhs. FEB, vol. 2, no. 2, pp. 1-9, 2014.
[13] R. W. Purubaya, P. B. Santoso, and R. A. Sari, "Pengendalian Persediaan Suku Cadang Mesin Produksi pada Departemen Maintenance dengan Pendekatan Periodic Review ( R,s,S ) System ( Studi Kasus di PT . Adi Putro Wirasejati )," J. Rekayasa dan Manaj. Sist. Ind., vol. 2, no. 6, pp. 1202-1213, 2014.

[14] E. Budiningsih and W. A. Jauhari, "Analisis Pengendalian Persediaan Spare Part Mesin Produksi di PT. Prima Sejati Sejahtera dengan Metode Continuous Review," PERFORMA Media Ilm. Tek. Ind., vol. 16, no. 2, pp. 152-160, 2017.

\section{BIOGRAFI PENULIS}

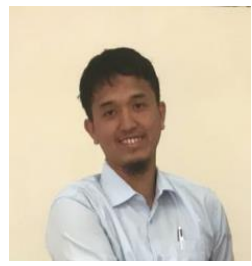

Sazli Tutur Risyahadi, STP, MT, MSi

Penulis lahir di Bogor, 4 April 1987. Saat ini penulis adalah Dosen di Program Studi Manajemen Industri IPB, dengan riwayat pendidikan adalah (S1) Teknologi Industri Pertanian di Institut Pertanian Bogor lulus tahun 2009, (S2) Teknik dan Manajemen Industri di Institut Teknologi Bandung lulus tahun 2012 dan (S2) Teknologi Pascapanen di Institut Pertanian Bogor lulus tahun 2015.

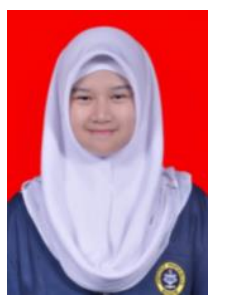

\section{Hanifah Yunan Putri}

Penulis lahir di Pandeglang pada tanggal 5 September 1998. Saat ini berusia $20^{\text {th }}$ dan sedang menempuh pendidikan Diploma 3 di Program Studi Manajemen Industri Sekolah Vokasi IPB, Selain itu, Pengalaman Organisasi dan Komunitas yang pernah diikuti oleh penulis dari tahun 2014sekarang adalah Purna Paskibraka Indonesia (PPI) Provinsi Banten dan Kabupaten Tangerang, Organisasi Siswa Intra Sekolah (OSIS), Bimbingan Belajar Pasca Ujian 
Nasional (BPUN), Yuk Berbagi Bogor,

Kelompok Pemerhati Lingkungan (KPL)

Angsana, Green Active Youth, Althafunnisa,

Aksaralogia, dan Vokasi IPB Mengajar. 